\title{
Phenolics Content, Antioxidant Activity and Color of Green Walnut Extracts for Preparing Walnut Liquor
}

\author{
Sina COSMULESCU ${ }^{1 *}$, Ion TRANDAFIR ${ }^{2}$, Violeta NOUR ${ }^{1}$, \\ Mira IONICA ${ }^{1}$, Felicia TUTULESCU ${ }^{1}$ \\ ${ }^{1}$ University of Craiova, Agriculture \& Horticulture Faculty, Department of Horticulture \& Food Science, A.I.Cuza Street, 13, Craiova, Romania; \\ sinacosmulescu@hotmail.com (*correspondingauthor),vionour@central.ucv.ro,miraelena29@yahoo.com, felixdragomir@yahoo.com \\ ${ }^{2}$ University of Craiova, Sciences Faculty, Department of Chemistry, Calea Bucuresti Street, 107, Craiova, Romania; nelutrandafir@yahoo.com
}

\begin{abstract}
Different extracts prepared from green fruits of 'Sibisel 44' walnut cultivar were investigated for their total phenolics and flavonoids, antioxidant activity, individual phenolics content and colour component. Extracts were prepared using three variants, to analyze the effect of solvent concentration and sugar addition on properties of green walnuts extracts. The antioxidant activity of alcoholic extracts was investigated by the 2,2'-diphenyl-1-picrylhydrazyl (DPPH) radical scavenging method while total phenolic content was determined by using the Folin-Ciocalteu assay. Seventeen individual phenolics were detected and quantified by using HPLC in walnut green fruit extracts. For total phenolics and flavonoids extraction from green walnut fruits $70 \%$ ethanol was more efficient. Highest concentration was found in samples with $70 \%$ ethanol for gallic, vanillic, chlorogenic, caffeic, syringic, salicylic, ellagic acids, juglone, catechin, epicatechin, myricetin, and quercetin. The use of $40 \%$ ethanol led to a significant increase of ferulic acid and rutin content, while the greatest amount of rutin was extracted using $40 \%$ ethanol and sugar.
\end{abstract}

Keywords: antioxidant activity, color component, polyphenols, walnut liqueur

\section{Introduction}

In Romanian folk medicine, walnut has many uses. It is said that green walnuts are a symbol of life and fecundity. Fruits (dry and green), green husk, kernels, barks and leaves are a source of phytochemicals that increase the value of walnut production, as well as offer utilisation for byproducts (Akbari et al., 2012; Cosmulescu and Trandafir 2012). In food preparation, jam and liqueur made of green walnut are among the most used recipes. Walnut liqueur is subject of research papers in literature. Stampar et al. (2006) consider traditional walnut liqueur a cocktail of phenolics. Leaves of walnut and green walnuts are particularly rich in phenolic compounds (Cosmulescu et al., 2014; Cosmulescu and Trandafir, 2012). Traditional walnut liqueur is made of green walnuts just prior to hardening of the endocarp and this drink is commonly used in folk medicine (Stampar et al., 2007). A strong influence of cultivar choice and picking on phenolics content in walnut liqueur was observed by Jakopic et al. (2007). Stampar et al. (2006) found that concentrations of individual phenolics in liqueur were quite low compared to the contents in green husks, due to the traditional way of making the liqueur. Processing variables are influencing the characteristics of walnut liqueur. Alamprese and Pompei (2005a) found that the highest content of phenolic substances and the highest antioxidant power was obtained with the least ripe batch of walnuts and that temperature and length of steeping have little effect on phenolic composition of nocino. Jakopic et al. (2008) found that the content of total phenolics and of some individual phenolic compounds (protocatechuic, sinapic and $p$ coumaric acids as well as 1,4-naphthoquinone) increased in walnut liqueur with increasing ethanol concentration. Stampar et al. (2006) identified fourteen phenolic compounds in walnut liqueur (chlorogenic acid, caffeic acid, ferulic acid, sinapic acid, gallic acid, ellagic acid, protocatechuic acid, syringic acid, vanillic acid, catechin; epicatechin, myricetin, 1,4-naphthoquinone, juglone) while Jakopic et al. (2007) quantified ten phenolic compounds (gallic, protocatechuic, ellagic, chlorogenic, syringic, $p$ coumaric, sinapic acids, catechin, 1,4-naphthoquinone and juglone).

In relation to the antioxidant properties of walnut extract, Negi et al. (2011) believe that walnut may act as a cancer chemopreventive agent, exhibiting high phenolic content, antioxidant activity, and potent antiproliferative activity. In a study of nocino liqueur samples aged for different lengths of time, Alamprese et al. (2005b) showed that total phenols, total tannins, non-tannin phenolics and antioxidant activity have remained unchanged during the aging process in the case of home-made nocino compared to the commercial products.

The aim of this work was to analyze the effect of ethanol concentration and sugar addition on the bioactive content and antioxidant activity of green walnuts hydroalcoholic 
extracts. Extracts were compared with respect to their total phenolics content, total flavonoids, individual phenolics content, antioxidant activity, and color.

\section{Materials and methods}

Green walnuts were collected in the second half of June 2013 from the experimental walnut orchard belonging to the Research Station of University of Craiova $\left(44^{\circ} 20^{\prime} \mathrm{N}\right.$, $23^{\circ} 49^{\prime}$ E). Walnuts of 'Sibisel $44^{\prime}$ ' cultivar were utilized in preparing the extracts. $200 \mathrm{~g}$ of knife crushed green walnuts were mixed with $400 \mathrm{~mL}$ of liquid, then placed in a sealed glass vessel and left to soak for 6 weeks. Walnut extracts were prepared in three solvents: (a) 70\% ethanol; (b) 40\% ethanol and sugar (ratio 1:1) - traditional recipe/method; (c) $40 \%$ ethanol in three repetitions. The extracts were filtered through Whatman cellulose nitrate membranes (0.8 $\mu \mathrm{m}$ pore size) and stored at $4^{\circ} \mathrm{C}$ until analysis.

\section{Total phenolics content}

Chemicals and reagents: Folin-Ciocalteu reagent $(2 \mathrm{~N}$, Sigma-Aldrich), gallic acid (Sigma-Aldrich), anhydrous sodium carbonate (Sigma-Aldrich), methanol were used in this experiment.

Method: Total phenolics content in the extracts was determined colorimetrically with Folin-Ciocalteu reagent by using the method described by Singleton and Rossi (1965) with some modifications (Cosmulescu and Trandafir, 2012). $5 \mathrm{~mL}$ Folin-Ciocalteu reagent (diluted 1:10 with ultrapure water) were added to $1 \mathrm{~mL}$ extract (diluted 1:20 with methanol) and stirred for one minute. After $2 \mathrm{~min}, 4 \mathrm{~mL}$ of sodium carbonate aqueous solution $7.5 \%$ were added and incubated for 2 hours at the room temperature (approx $25^{\circ} \mathrm{C}$ ). The absorbance of the mixture was measured at $765 \mathrm{~nm}$ using an Evolution $600 \mathrm{UV} / \mathrm{VIS}$ spectrophotometer (Thermo Scientific, USA). Gallic acid was used to prepare the standard curve $(0-250 \mathrm{mg} / \mathrm{L})$. Gallic acid was used as reference standard and results were expressed as gallic acid equivalents in milligrams per liter of extract (mg GAE/L).

\section{Total flavonoids content}

Chemicals and reagents: Methanol (Merck), aluminium nitrate (Sigma-Aldrich), potassium acetate (Sigma-Aldrich), quercetin (Sigma-Aldrich) were used in this experiment.

Methods: Determination of flavonoids was done by aluminium nitrate colorimetric method described by Rahimipanah et al. (2010) and Mohammadzadeh et al. (2007). Briefly, $0.5 \mathrm{~mL}$ of extract was diluted with methanol $(1: 10)$ and mixed in a test tube with $0.1 \mathrm{~mL}$ of $10 \%$ aluminium nitrate, $0.1 \mathrm{~mL}$ of $1 \mathrm{M}$ aqueous potassium acetate and $4.3 \mathrm{~mL}$ methanol. After keeping for $40 \mathrm{~min}$ at room temperature, the absorbance of the reaction mixture was measured at $415 \mathrm{~nm}$. Quercetin was used for preparing the standard curve $(0-100 \mathrm{mg} / \mathrm{L})$. The results were expressed as milligrams of quercetin equivalents per liter (mg QE/L).

\section{Antioxidant Activity}

Chemicals and reagents: Methanol (Merck), 2,2diphenyl-1-picrylhydrazyl (DPPH; Merck), ascorbic acid (Merck), were used in this experiment.
Method: The capacity of scavenging the 2,2-diphenyl-1picrylhydrazyl free radical was monitored according to the method reported by Cosmulescu and Trandafir (2012). Briefly, $50 \mu \mathrm{L}$ of sample extracts were mixed with $3 \mathrm{~mL}$ of methanolic solution which is containing DPPH radicals ( 40 $\mathrm{mg} / \mathrm{L})$. The mixture was kept in dark for 30 minutes, and the absorbance was measured at $517 \mathrm{~nm}$. All assays were conducted in triplicate. Standards of ascorbic acid with various concentrations $(0-200 \mathrm{mg} / \mathrm{L})$ were used. Antioxidant capacity was expressed in $\mathrm{mg}$ ascorbic acid equivalents per liter.

\section{Individual phenolics and juglone}

Chemicals and reagents: Standards of phenolic acids (gallic, vanillic, chlorogenic, caffeic, syringic, $p$-coumaric, ferulic, sinapic, salicylic, ellagic and trans-cinnamic), flavonoids (catechin, epicatechin, rutin, myricetin and quercetin) and juglone (Sigma-Aldrich, Germany), methanol (HPLC grade, Baker, Netherlands), acetic acid (HPLC grade, Merck, Germany) and BHT (Sigma-Aldrich, Germany) were used in this experiment.

Method: Phenolics were extracted from a $1000 \mathrm{mg}$ sample in a DK 102 p Bandelin ultrasonic bath with $20 \mathrm{ml}$ methanol and 1\% BHT (2,6-di-tert-butyl-4-methylphenol) at $25^{\circ} \mathrm{C}$ for $40 \mathrm{~min}$. The extracts were centrifuged at $1200 \mathrm{~g}$ and the supernatants were filtered through a $0.2 \mu \mathrm{m}$ polyamide membrane and then stored at $-20{ }^{\circ} \mathrm{C}$. HPLC analyses were performed on a Finningan Surveyor Plus HPLC system (Thermo Electron Corporation, San Jose, CA). Separation was achieved by a reversed-phase Hypersil Gold C18 column ( $5 \mu \mathrm{m}$ particle size, 250 x $4.6 \mathrm{~mm}$ ) provided by Thermo Electron Corporation. According to Nour et al. (2013), the mobile phase consisted of $1 \%$ aqueous acetic acid solution (A) and methanol (B). Samples were eluted with the following gradient: $90 \%$ A from 0 to $27 \mathrm{~min}$, from 90 to $60 \% \mathrm{~A}$ in $28 \mathrm{~min}, 60 \%$ A for $5 \mathrm{~min}$, from 60 to $56 \% \mathrm{~A}$ in $2 \mathrm{~min}, 56 \%$ A for $8 \mathrm{~min}$, from 56 to $90 \% \mathrm{~A}$ in $1 \mathrm{~min}$ and $4 \mathrm{~min} 90 \% \mathrm{~A}$ to re-establish the initial conditions, before the injection of another sample. All gradients were linear. The flow rate was $1 \mathrm{~mL} / \mathrm{min}$ and injection volume was $5 \mu \mathrm{L}$. Column temperature was maintained at $20^{\circ} \mathrm{C}$. Each compound was identified by its retention time and by spiking with standards under the same conditions. Identities of constituents were also confirmed with a photodiode array (PDA) detector by comparison with ultraviolet (UV) spectra of standards in the wavelength range of $220-450 \mathrm{~nm}$. Each compound was quantified according to peak area measurements, which were reported in calibration curves of corresponding standards. All samples were extracted and analyzed in triplicate. The contents of investigated phenolic compounds were expressed in $\mathrm{mg} / \mathrm{L}$ fresh weight $(\mathrm{FW})$ as mean values \pm standard deviations.

\section{Measurement of color by the $C I E L^{*} a^{*} b^{*}$ system}

The CIEL* $\mathrm{a}^{*} \mathrm{~b}^{*}$ system (International Commission on Illumination, Vienna) has been embraced by the US food industry for measuring color of food products. Absorbance of undiluted samples was measured in quartz cuvettes with a path length of $0.1 \mathrm{~cm}$ from 350 to $850 \mathrm{~nm}$ using an Evolution 600 spectrophotometer. L* (lightness), a* 
(red/green colour component), b* (yellow/blue colour component) were determined using the color analysis program VL-ColorCalc. Chroma (C) or saturation and hue angle $(\mathrm{H})$ or tones were determined considering McGuire (1992): $\mathrm{C}=\left(\mathrm{a}^{* 2}+\mathrm{b}^{* 2}\right)^{1 / 2} ; \mathrm{H}=\operatorname{arctangent}$ of $\mathrm{b}^{*} / \mathrm{a}^{*}$.

\section{Statistical Analysis}

Data were evaluated by one-way analysis of variance (ANOVA) using Statgraphics Centurion XVI software (StatPoint Technologies, Warrenton, VA). Differences in content levels among the variants were estimated with a multiple range test based on Fisher's least significant difference (LSD) procedure at $\mathrm{P}<0.05$.

\section{Results and discussions}

Total flavonoid, total phenolics content and antioxidant capacity in green walnut extracts

Starting from the idea of using walnut green fruit extract for preparing liqueur, the present study was focused on the hydroalcoholic extraction of phenolics. Walnut green fruits were extracted with $70 \%$ ethanol (a); $40 \%$ ethanol and sugar (b); $40 \%$ ethanol (c). Results of total flavonoids, total phenolics content and antioxidant capacity in green walnut extracts are presented in Tab. 1. In liqueur, phenolics contribute to astringent but pleasant taste (Stampar et al., 2006) and low risk of some chronic diseases may be associated at higher dietary flavonoid intakes (Knekt et al., 2002). In the present study, in walnut extracts, total phenolics content ranged from $2365 \mathrm{mg}$ gallic acid/L to $4610 \mathrm{mg}$ gallic acid/L and total flavonoids content from $171.02 \mathrm{mg}$ quercetin/L to $423.97 \mathrm{mg}$ quercetin/L.

There were significant differences $(\mathrm{P}<0.05)$ among phenolic contents and total flavonoids of extracts using the variants mentioned (Tab. 1).

The highest phenolic levels and also flavonoids were obtained at extractions in 70\% ethanol, followed by extractions in 40\% ethanol and sugar (ratio 1:1) and in 40\% ethanol. It shows that high concentration of ethanol (70\%) is causing high content in total flavonoids and total phenolics, and at the same ethanol concentration (40\%), the addition of sugar increases their amount. The result is similar to that previously obtained by other researchers. Other studies have established that extraction yield of phenols is greatly dependent on solvent and solvent concentration (Stampar et al., 2006). In walnut alcoholic drink, total phenolic content increased with increasing ethanol concentration (Jakopic et al., 2008). On the effectiveness of solvent, Jakopic et al. (2009) concluded that the amounts of total phenolics were higher when methanol was used for extraction of phenolic compounds from green walnut fruits. In order to optimise extraction process and the quality of extracts, Fernández-Agulló et al. (2013) propose the factors to consider in future studies would be temperature, time and solid to liquid ratio. The maximum flavonoid / phenolic ratio (0.116) was found in green walnut extracts obtained in variant (b) - $40 \%$ ethanol and sugar - thus indicating that more flavonoids are extracted in this variant. In terms of antioxidant capacity the variation was similar, the highest antioxidant capacity was found in extracts made in $70 \%$ ethanol (Tab. 1). The antioxidant capacity of green walnut extracts ranged from $4175 \mathrm{mg}$ Trolox equivalents/L to $7850 \mathrm{mg}$ Trolox equivalents/ $\mathrm{L}$ (Tab. 1). Alamprese et al. (2005b) studied the antioxidative potential of walnut liqueur and showed that antioxidant activity was directly correlated with total phenolics content and this characteristic did not change during storage, even for many years. The highest value of antioxidant activities and total phenolic contents were determined in bilberry, blackberry and black mulberry wines by Kalkan Yildirim (2006). Mrvcic et al. (2013) examined a number of 46 spirit drinks and liqueurs produced in Croatia and concluded that walnut or sour cherry liquors contained the most polyphenols and had very high antioxidant activity.

\section{Phenolic profile of green walnut extracts}

The contents and retention time of individual phenolic compounds in green walnut extracts are presented in Tab. 2 . There were identified and quantified eleven phenolic acids (gallic, vanillic, chlorogenic, caffeic, syringic, $p$-coumaric, ferulic, sinapic, salicylic, ellagic and trans-cinnamic), five flavonoids (catechin, epicatechin, rutin, myricetin and quercetin) and juglone in green walnut extracts. Regarding gallic acid, this study found an average content between 66.72 and $55.12 \mathrm{mgGAE} / \mathrm{L}$. Gallic acid was the major phenolic compound in walnut liqueur found by Stampar $e t$ al. (2006).

Previous experimental results have indicated that ellagic acid is the dominating phenolic acid of walnut leaves, followed by trans-cinnamic, chlorogenic and caffeic acids (Nour et al., 2013). There were significant differences among samples in all individual phenolic acids. Highest concentration was found in $70 \%$ ethanol samples (a) for gallic, vanillic, chlorogenic, caffeic, syringic, salicylic and ellagic acid. The use of $40 \%$ ethanol (c) led to significantly increase in ferulic acid. Determinations revealed also high concentrations of flavonoids. Catechin, a strong antioxidant that scavenges radicals (Alshatwi, 2010) was established as

Tab. 1. Total flavonoid, total phenolics content and antioxidant capacity in green walnut extracts $(\mathrm{mg} / \mathrm{L})$

\begin{tabular}{ccccc}
\hline Solvents & Total phenolics content & Total flavonoid content & Antioxidant capacity & $\begin{array}{c}\text { Flavonoid/ } \\
\text { Phenolics }\end{array}$ \\
\hline a & $4610 \pm 262.73^{\mathrm{c}}$ & $423.97 \pm 10.37^{\mathrm{c}}$ & $7850 \pm 337.55^{\mathrm{c}}$ & $0.092 \pm 0.003^{\mathrm{b}}$ \\
b & $3182 \pm 108.24^{\mathrm{b}}$ & $370.42 \pm 13.22^{\mathrm{b}}$ & $5330 \pm 245.18^{\mathrm{b}}$ & $0.116 \pm 0.002^{\mathrm{c}}$ \\
c & $2365 \pm 78.53^{\mathrm{a}}$ & $171.02 \pm 6.84^{\mathrm{a}}$ & $4175 \pm 212.92^{\mathrm{a}}$ & $0.072 \pm 0.005^{\mathrm{a}}$ \\
\hline
\end{tabular}

Data expressed as means \pm SE of three samples analyzed separately. ${ }^{*}$ gallic acid equivalents; ${ }^{* *}$ quercetin equivalents; ${ }^{* * *}$ Trolox equivalents. Different superscript letters within the same column indicate significant differences $(\mathrm{P}<0.05)$ among solvents 
Tab. 2. Phenolic compounds in green walnut extracts $(\mathrm{mgGAE} / \mathrm{L})$

\begin{tabular}{lcccc}
\hline \multicolumn{1}{c}{ Phenolics } & Retention time $(\min )$ & Solvent a & Solvent b & Solvent c \\
\hline Gallic acid & 5.25 & $66.72 \pm 3.07^{\mathrm{b}}$ & $65.18 \pm 2.34^{\mathrm{b}}$ & $55.12 \pm 3.36^{\mathrm{a}}$ \\
(+)-Catechin & 18.42 & $530.80 \pm 15.39^{\mathrm{b}}$ & $504.60 \pm 22.21^{\mathrm{b}}$ & $257.33 \pm 10.33^{\mathrm{a}}$ \\
Vanillic acid & 28.09 & $9.53 \pm 0.43^{\mathrm{b}}$ & $7.65 \pm 0.29^{\mathrm{a}}$ & $8.07 \pm 0.45^{\mathrm{a}}$ \\
Chlorogenic acid & 28.90 & $16.20 \pm 0.68^{\mathrm{c}}$ & $3.77 \pm 0.21^{\mathrm{a}}$ & $6.47 \pm 0.32^{\mathrm{b}}$ \\
Caffeic acid & 30.95 & $2.20 \pm 0.09^{\mathrm{c}}$ & $0.33 \pm 0.02^{\mathrm{a}}$ & $0.44 \pm 0.02^{\mathrm{b}}$ \\
Acid syringic & 37.58 & $23.00 \pm 1.06^{\mathrm{b}}$ & $18.37 \pm 0.69^{\mathrm{a}}$ & $17.28 \pm 0.98^{\mathrm{a}}$ \\
(-)-Epicatechin & 40.39 & $350.33 \pm 11.91^{\mathrm{b}}$ & $337.31 \pm 13.49^{\mathrm{b}}$ & $167.41 \pm 6.62^{\mathrm{a}}$ \\
\hline -Coumaric acid & 45.95 & $15.21 \pm 0.72^{\mathrm{a}}$ & $18.27 \pm 0.96^{\mathrm{b}}$ & $14.59 \pm 0.87^{\mathrm{a}}$ \\
Ferulic acid & 49.53 & $12.80 \pm 0.43^{\mathrm{a}}$ & $11.70 \pm 0.38^{\mathrm{a}}$ & $24.82 \pm 0.96^{\mathrm{b}}$ \\
Sinapic acid & 51.63 & $23.84 \pm 1.22^{\mathrm{a}}$ & $78.63 \pm 3.61^{\mathrm{c}}$ & $34.90 \pm 1.81^{\mathrm{b}}$ \\
Salicylic acid & 52.04 & $186.58 \pm 6.34^{\mathrm{c}}$ & $50.96 \pm 2.47^{\mathrm{b}}$ & $26.39 \pm 1.26^{\mathrm{a}}$ \\
Rutin & 57.24 & $44.57 \pm 2.22^{\mathrm{b}}$ & $74.70 \pm 3.43^{\mathrm{c}}$ & $33.56 \pm 1.87^{\mathrm{a}}$ \\
Ellagic acid & 58.51 & $32.19 \pm 1.65^{\mathrm{c}}$ & $19.08 \pm 1.08^{\mathrm{b}}$ & $12.86 \pm 0.66^{\mathrm{a}}$ \\
Myricetin & 61.56 & $20.76 \pm 0.98^{\mathrm{c}}$ & $11.80 \pm 0.45^{\mathrm{b}}$ & $5.34 \pm 0,31^{\mathrm{a}}$ \\
Juglone & 62.73 & $34.40 \pm 1.33^{\mathrm{c}}$ & $22.42 \pm 0.88^{\mathrm{b}}$ & $12.47 \pm 0.54^{\mathrm{a}}$ \\
Trans-cinnamic acid & 68.63 & $0.32 \pm 0.02^{\mathrm{b}}$ & $2.74 \pm 0.14^{\mathrm{c}}$ & $0.12 \pm 0.01^{\mathrm{a}}$ \\
Quercetin & 70.68 & $8.16 \pm 0.43^{\mathrm{c}}$ & $5.82 \pm 0.26^{\mathrm{b}}$ & $5.04 \pm 0.31^{\mathrm{a}}$ \\
\hline
\end{tabular}

Data expressed as means $\pm \mathrm{SE}$ of three samples analyzed separately. Different superscript letters between the same column indicate significant differences $(\mathrm{P}<0.05)$ among solvents

Tab. 3. CIEL $\mathrm{a}^{*} \mathrm{~b}^{*}$ parameters for three differently extracts in green walnut

\begin{tabular}{cccc}
\hline \multirow{2}{*}{ Parameters } & \multicolumn{3}{c}{ Solvents } \\
\cline { 2 - 4 } & $\mathrm{a}$ & $\mathrm{b}$ & $\mathrm{c}$ \\
\hline $\mathrm{L}^{*}$ & $81.4 \pm 1.95^{\mathrm{b}}$ & $68.6 \pm 1.57^{\mathrm{a}}$ & $7.3 \pm 2.16^{\mathrm{c}}$ \\
$\mathrm{a}^{*}$ & $16.4 \pm 0.76^{\mathrm{c}}$ & $13.6 \pm 0.53^{\mathrm{b}}$ & $26.9 \pm 1.07^{\mathrm{a}}$ \\
$\mathrm{b}^{*}$ & $38.4 \pm 1.36^{\mathrm{b}}$ & $28.4 \pm 0.85^{\mathrm{a}}$ & $27.87 \pm 0.94^{\mathrm{a}}$ \\
$\mathrm{C}=\left(\mathrm{a}^{* 2}+\mathrm{b}^{* 2}\right)^{1 / 2}$ & $41.75 \pm 0.95^{\mathrm{c}}$ & $31.48 \pm 0.51^{\mathrm{b}}$ & $74.816 \pm 1.23^{\mathrm{b}}$ \\
\hline $\mathrm{H}^{\mathrm{o}}=$ arctangent $\mathrm{b}^{*} / \mathrm{a}^{*}$ & $66.873 \pm 1.69^{\mathrm{a}}$ & $64.411 \pm 1.61^{\mathrm{a}}$ & \\
\hline
\end{tabular}

All data are expressed as average value \pm standard deviation. Different superscript letters between columns indicate significant differences $(\mathrm{P}<0.05)$ among solvents

the dominating flavonoid of green walnut extracts, followed by epicatechin, rutin, myricetin and quercitin. Catechin was found in concentrations between 257.33 and 530.8 mgGAE/L, while quercetin was found in concentrations between 5.04 and $8.16 \mathrm{mgGAE} / \mathrm{L}$. Myricetin, one of the most common flavonols with potent anticarcinogen and antimutagen activities (Ong and Khoo, 1997), was found in concentrations between 20.76 and $5.34 \mathrm{mgGAE} / \mathrm{L}$. High content of flavonoids was found in variant (a), except rutin, while the greatest amount of rutin was found in variant (b).

Juglone is known as the characteristic compound of Juglans spp. and is reported to occur in different parts of walnut (Jakopič et al., 2009). The highest juglone levels (Tab. 2) were obtained at extractions in $70 \%$ ethanol (a), followed by extractions in $40 \%$ ethanol and sugar (b) and in $40 \%$ ethanol (c). As regards the amounts of juglone content in extracts from green walnut fruits, Jakopic et al. (2009) concluded that content is higher when methanol was used for extraction, compared to ethanol.

\section{Measurement of color by the CIEL ${ }^{*} a^{*} b^{*}$ system}

To investigate color quality of the three extracts, lightness and color components were measured. Tab. 3 presents the results of color evaluation of the green walnut extracts using the CIEL*a* ${ }^{*}$ color system. Significant differences of yellow/blue color component $\left(\mathrm{b}^{*}\right)$, red/ green $\left(a^{*}\right)$ color component, values of lightness $\left(L^{*}\right)$, hue angle and chroma $(\mathrm{C})$ were obtained for extracts from green walnut.

Tab. 3 shows that lightness $\left(\mathrm{L}^{*}\right)$ decreased at lower ethanol concentration ( $40 \%)$ and sugar addition (variant b) and increased at variant (c) - 40\% ethanol. Indicators $a^{*}$ and $b^{*}$ decreased at variants (b) and (c) compared to variant (a), along with the decrease of alcohol concentration and sugar addition. $\mathrm{L}^{*}$ is the indicator of lightness-darkness and the higher it is, the lighter the extracts. In this case, $40 \%$ ethanol extraction solution was the most transparent. Parameters $\mathrm{a}^{*}$ and $\mathrm{b}^{*}$ have recorded positive values, thus pointing out a greater contribution of red and yellow components. Intensity or saturation (C) is higher in the extract (a) 70\% ethanol and hue angle $\left(\mathrm{H}^{\circ}\right)$ in the $40 \%$ ethanol. Hue angle presented values between $64.41-74.8^{\circ}$ from red purple $\left(0^{\circ}\right)$ to yellow $\left(90^{\circ}\right)$.

\section{Conclusions}

We can conclude that the extraction efficiency of flavonoid and phenolics from green walnut fruits and the color quality of the extract depend on the methods used. For total phenolics and flavonoid extraction from green walnut fruits, $70 \%$ ethanol was more efficient. Highest concentrations were found in $70 \%$ ethanol samples for gallic, vanillic, chlorogenic, caffeic, syringic, salicylic, ellagic 
555

acid, juglone, catechin, epicatechin, myricetin, and quercetin. The use of $40 \%$ ethanol led to a significant increase of ferulic acid and rutin, while the greatest amount of rutin was found in the extract made in $40 \%$ ethanol and sugar. Hue angle $\left(\mathrm{H}^{\circ}\right)$ of the extracts presented values between $64.41-74.81^{\circ}$ from red purple $\left(0^{\circ}\right)$ to yellow $\left(90^{\circ}\right)$. The results suggest that, for food value purpose, green walnut fruit is a valuable raw material for obtaining quality liquor and the $70 \%$ ethanol extract provides the highest amount of phenolics and flavonoids. Considering the fact that concentration of alcohol in the liqueur is up to $45 \%$, the traditional version ( $40 \%$ ethanol and sugar) of preparing the extract may be a viable alternative. Further research is needed on the quality of the liquor.

\section{Acknowledgement}

This work was partially supported by the grant number $11 \mathrm{C} / 2014$, awarded in the internal grant competition of the University of Craiova, Romania.

\section{References}

Akbari V, Jamei R, Heidari R, Esfahlan A J (2012). Antiradical activity of different parts of walnut (Juglans regia $\mathrm{L}$.) fruit as a function of genotype. Food Chem 135(4):2404-2410.

Alamprese C, Pompei C (2005a). Influence of processing variables on some characteristics of nocino liqueur. Food Chem 92(2):203-209.

Alamprese C, Pompei C, Scaramuzzi F (2005b). Characterization and antioxidant activity of nocino liqueur. Food Chem 90(4):495-502.

Alshatwi A (2010). Catechin hydrate suppresses MCF-7 proliferation through TP53/Caspase-mediated apoptosis. J Exp Clin Canc Res 29:167.

Cosmulescu S, Trandafir I (2012). Anti-oxidant activities and total phenolics contents of leaf extracts from 14 cultivars of walnut (Juglans regia L.). J Hortic Sci Biotech 87(5):504-508.

Cosmulescu S, Trandafir I, Nour V (2014). Seasonal variation of the main individual phenolics and juglone in walnut (Juglans regia) leaves. Pharm Biol 52(5):575-580.

Fernández-Agulló A, Pereira E, Freire MS, Valentão P, Andrade PB, González-Álvarez J, Pereira JA (2013). Influence of solvent on the antioxidant and antimicrobial properties of walnut (Juglans regia L.) green husk extracts. Ind Crops Prod 42:126-132.

Jakopic J, Colaric M, Veberic R, Hudina M, Solar A, Stampar F (2007). How much do cultivar and preparation time influence on phenolics content in walnut liqueur? Food Chem 104(1):100-105.
Jakopic J, Solar A, Colaric M, Hudina M, Veberic R, Stampar F (2008). The influence of ethanol concentration on content of total and individual phenolics in walnut alcoholic drink. Acta Aliment 37(2):233-239.

Jakopic J, Veberic R, Stampar F (2009). Extraction of phenolic compounds from green walnut fruits in different solvents. Acta Agr Slov 93(1):11-15.

Kalkan Yildirim H (2006). Evaluation of colour parameters and antioxidant activities of fruit wines. Int J Food Sci Nutr 57(12):47-63.

Knekt P, Kumpulainen J, Järvinen R, Rissanen H, Heliövaara M, Reunanen A, Hakulinen T, Aromaa A (2002). Flavonoid intake and risk of chronic diseases. Am J Clin Nutr 76(3):560568.

McGuire RG (1992). Reporting of objective color measurements. HortScience 27:1254-1255.

Mohammadzadeh S, Sharriatpanahi M, Hamedi M, Amanzadeh Y, Sadat Ebrahimi SE, Ostad SN (2007). Antioxidant power of Iranian propolis extract. Food Chem 103:729-733.

Mrvčić J, Posavec S, Kazazić S, Stanzer D, Peša A, Stehlik-Tomas V (2013). Spirit drinks: a source of dietary polyphenols. Croat J Food Sci Technol 4(2):102-111.

Negi AS, Luqman S, Srivastava S, Krishna V, Gupta N, Darokar MP (2011). Antiproliferative and antioxidant activities of Juglans regia fruit extracts. Pharm Biol 49(6):669-673.

Nour V, Trandafir I, Cosmulescu S (2013). HPLC determination of phenolic acids, flavonoids and juglone in walnut leaves. J Chromatogr Sci 51(9):883-890.

Ong KC, Khoo HE (1997). Biological effects of myricetin. Gen Pharmacol Vasc Syst 29(2):121-126.

Rahimipanah M, Hamedi M, Mirzapour M (2010). Antioxidant activity and phenolic contents of Persian walnut (Juglans regia L.) green husk extract. Afr J Food Sci Technol 1(4):105-111.

Singleton VL, Rossi JA (1965). Colorimetry of total phenolics with phosphomolybdic - phosphotungstic acid reagent. Am J Enol Viticult 16:144-158.

Stampar F, Solar A, Hudina M, Veberic R, Colaric M (2006). Traditional walnut liqueur - cocktail of phenolics. Food Chem 95(4):627-631.

Stampar F, Solar A, Hudina M, Veberic R, Colaric M, Fabcic J (2007). Phenolics in walnut liqueur. Acta Hort 744:451-454. 